\title{
Rural Credit and Farms Efficiency: Modelling Farmers Credit Allocation Decisions, Evidences from Benin
}

\author{
Comlan Hervé Sossou, ${ }^{1,2}$ Freddy Noma, ${ }^{3,4}$ and Jacob A. Yabi ${ }^{4}$ \\ ${ }^{1}$ Unit of Economy and Rural Development, Gembloux Agro-Bio-Tech, University of Liege, Passage des Déportés, \\ 5030 Gembloux, Belgium \\ ${ }^{2}$ Program of Agricultural Policy Analysis (PAPA), National Institute of Agricultural Researches of Benin (INRAB), \\ 01 BP 128 Porto-Novo, Benin \\ ${ }^{3}$ Institute of Project and Regional Planning, Faculty of Agriculture, Nutrition, and Environmental Management, \\ Justus-Liebig University of Giessen, Senckenbergstraße 3, 35390 Giessen, Germany \\ ${ }^{4}$ Department of Agricultural Economics and Rural Sociology, Faculty of Agronomy, University of Parakou, BP 123 Parakou, Benin
}

Correspondence should be addressed to Freddy Noma; orounoma@yahoo.fr

Received 23 April 2014; Revised 4 August 2014; Accepted 4 August 2014; Published 28 August 2014

Academic Editor: Thanasis Stengos

Copyright (C) 2014 Comlan Hervé Sossou et al. This is an open access article distributed under the Creative Commons Attribution License, which permits unrestricted use, distribution, and reproduction in any medium, provided the original work is properly cited.

\begin{abstract}
This paper analyses farmers' credit allocation behaviors and their effects on technical efficiency. Data were collected from 476 farmers using the multistage sampling procedure. The stochastic frontier truncated-normal with conditional mean model is used to assess allocation schemes effects on technical efficiency. Tobit model reveals the impact of farmers' sociodemographic characteristics on efficiency scores. Results reveal that farm revenue (about 2,262,566 Fcfa on average) is positively correlated with land acreage, quantity of labour, and costs of fertilizers and insecticides. Farmers' behaviors respond to six schemes which are categorized in two allocations contexts: out-farm and in-farm allocations. The model shows that only scheme (e) positively impacts technical efficiency. This scheme refers to the decision to invest credit to purchase better quality of pesticides, herbicides, fertilizers, and so forth. The positive effect of the scheme (c) may be significant under conditions of farmers' education level improvement. Then, scheme (e) is a better investment for all farmers, but effect of credit allocation to buy agricultural materials is positive only for educated farmers. Efficiency scores are reduced by household size and gender of the household head. Therefore a household with more than 10 members and a woman as head is likely to not be technically efficient.
\end{abstract}

\section{Introduction}

In Benin, $75 \%$ of the total population is involved in agriculture. The sector accounts for about $29.89 \%$ of the gross domestic product (GDP) and roughly $80 \%$ of the exportation shares [1]. Smallholder farmers are the most representative actors in Beninese agriculture and the increase of their productivity requires the adoption of improved technologies [2]. However, the adoption of these technologies needs to be supported by a rural funding system, which fits with smallholder famers features and needs [2]. Given that smallholder farmers are poor and often suffer a lack of institutional services [3]; improvement of the farm productivity could be achieved by a better access to agricultural credit. Access to credit services is identified as one of the most important constraints to the development of agriculture in Benin. Only $14 \%$ of the credit offer in Economic Community of West African States (ECOWAS) is towards agriculture [4]. Furthermore, according to [5], Benin Microfinance Institutions offer 79.18\% of their funding services to the business sector and $16.4 \%$ to agriculture. Besides the issues of access to credit and the amounts offer which are less in comparison to farmers' needs, there is the problem of credit refunding. In this paper, we assume that one reason of this recurrent phenomenon is poor farmers' allocation behaviors. And these behaviors do not permit to gain profit from the credit investment and be able to refund the loan. The aim of the study is to assess the effect of Benin farmers' credit allocation decisions on their technical 
efficiency. In fact developing countries farmers allocate the credit obtained in two ways: (1) investments in household and social requirements: debts refunding, weddings, death, housing, health, and so forth; and (2) investments in farming requirements: inputs purchasing, labor, and so forth. In this paper we model the credit investments in these two situations to identify which combination allows improving technical efficiency. Based on the credit allocation decisions, we set the following hypotheses: $H_{0}$ : credit investments in farming requirements improve technical efficiency, $H_{1}$ : credit investments in farming requirements do not improve technical efficiency.

\section{Literature Review}

A study on the influence of access to credit on technical efficiency has been led in Chile. Crops producers and livestock producers were sampled. The translog stochastic frontier function has been used to capture the effect of credit provision on these specialized small farmers. Results show that credit access and credit volume have opposite effects on crop production and livestock production, respectively [6]. In Ethiopia, the influence of credit on both constrained and unconstrained households has been assessed [7]. The idea is to capture efficiencies differences between these categories. Results show that credit constrained households are $12 \%$ less efficient than the ones unconstrained. Besides, education level, land fragmentation, and loan size are significant sources of inefficiency between these groups.

In [8], the stochastic frontier analysis was used to assess institutional credit impact on farm production efficiency in Pakistan. The mean efficiency score is 0.84 indicating $16 \%$ of inefficiency. Farming experience, education, access to farming credit, herd size, and number of cultivation practices has significant effects on farmers' technical efficiency. Moreover, the variable credit has the highest coefficient value: showing the importance of agricultural credit to farmers. In Nigeria, [9] classified farmers into beneficiaries and nonbeneficiaries to understand how the lack of capital affects their productivity. The capital here is the provision of credit or not. As results, farm production operations are correlated with the investment of credit towards crop production, the adoption of new technologies, and proper processing and storage. All that depends on farmers' socioeconomic status and its way to understand and deal with issues: its behaviour.

In the above mentioned studies, analysis focused on credit provision impacts on different groups and types of farm households. None of them took account of the step after getting the credit: farmer allocation behaviour. In fact, farmers have several ways to manage the credit obtained and they differently affected farms production efficiency. Therefore farmers' credit allocation behaviors is a relevant topic worthy to highlight. The current paper is the first to model farmer credit allocation behaviours and to assess their impacts on farms technical efficiency in Sub-Sahara Africa.

\section{Methodology}

Data were collected in the whole country and a total of 476 farmers were interviewed. The multiple stage multistage sampling procedure was used to target the areas covered by development projects offering microfinance services and the farmers involved. A total of 20 districts with an average of 25 farmers per district were accounted in the study.

Multistage sampling is a procedure allowing dividing a population into groups: this is the first stage. The second stage is the choice of some groups from the ones obtained from the first stage; this is randomly done. Then households are selected from the chosen groups: this is the third stage. In this study the choice of surveyed areas is based on microfinance services coverage rate. And the selection of surveyed households is based on the criteria of attendance to microfinance services. The advantages of this sampling procedure are: data collection costs reduction; data collection feasibility: it is the whole population no more but representative groups which constitute the sample. It is appropriate for this survey because everyone does not have access to credit, then it permits to target the beneficiaries, while accounting for the sample representativeness in the total population.

\section{Theoretical Framework}

The theoretical background relies on the neoclassic theory which states that the objective of all company is to maximize its profit [10]. A company allocates resources according to market conditions so that to maximize its profit. Thus a farmer is rational when for producing a specific output, with $n$ inputs $x=x_{1} \cdots x_{2}$, purchased at prices $w=$ $w_{1} \cdots w_{2}$; the production system runs on the production frontier. Meaning that, for fixed inputs the production system optimizes the inputs combination so as the outputs are closer to the production frontier. Then, technical efficiency (TE) seeks the best inputs combination allowing being closer to the production frontier. And any other deviations from the production frontier measure the technical inefficiency (TI) of the production system [11]. A production system which optimizes the inputs combination to reach a fixed output level is input-oriented. It is output-oriented for fixed quantities of inputs to reach the optimal level of outputs; this is the case for most agricultural production systems. In fact, farmers decide the quantities of inputs to use before producing, then quantities are fixed and during the farming process farmers try to optimize their yields.

\section{Empirical Framework}

Two approaches are used to analyze TE: (1) the parametric approach and (2) the nonparametric approach [12]. The parametric approach involved two methods. The first is (1) the estimation of TE scores and a Tobit regression with farmers sociodemographics features to identify TE scores determinants. From an econometric view, this model is not consistent with the independent and identically distributed assumption. The second method (2) is estimation in one step of the TE and its determinants. It is done by "stochastic 
frontier truncated-normal: conditional mean with explanatory variable" model. This model has been used by $[6,8,13]$ to estimate TE of several economic sectors. Dinar et al. [14] used the same model to assess the effects of the access to extension services on farms TE. It allows capturing the double effect of the variable of interest as production input and as determinant of TE of a production system. Here the variables of interest are the amount of credit given and farmers divers' allocation schemes of the credit. The determinants of TE are of two types: (1) human capital: age, gender, education level, and farming experience; and (2) institutional features: access to credit, access to extension services, and so forth. To capture the effect of the credit allocation schemes on the farms TE, the one step stochastic model is used. And a Tobit model with the human capital variables is used to identify the determinants of the TE scores.

5.1. The Stochastic Frontier Model. The hypothesis is the credit alone and in combination with the production inputs increase the production system TE. In this scheme the credit is a production input and, in combination with others inputs (labour, pesticides, capital, etc.), it determines farms TE. This combination is mathematically showed by the interaction between the variable credit and the inputs variables. And each variable obtained from this interaction represents the credit allocation scheme; for example, a variable credit $\times$ labour showed the allocation of the credit to increase the quantity of labour needed. The effects of these interactions are captured by the following stochastic model:

$$
y_{i}=f\left(x_{i}\right) \exp \left(v_{i}-u_{i}\left(z_{i}\right)\right),
$$

where $y_{i}$ is the production level of a farm $i ; x_{i}$ is the vector of inputs; $f(\cdot)$ represents the production frontier; and $w_{i}=$ $v_{i}-u_{i}$ is the composite error term. The error term $v_{i}$ is related to the omitted variables and factors uncontrollable by the farmer, such as climate variability and soil fertility. $u_{i}$ is a nonnegative component, accounting for the inefficiency; such as the TE output-oriented is $E T_{i}=\exp \left(-u_{i}\right) \in[0,1][12$, $15,16]$. The output-oriented approach fits with agricultural production; in this system the inputs quality and quantity are predetermined before starting the production process [17]. Then, in the production function, there is no link between the stochastic error term and the predetermined inputs. Equation (1) estimation will not present simultaneity bias [14, 18]. The assumptions on the error terms are $u_{i}$ is half-normal distributed; $v_{i}$ normal distributed and $\operatorname{Cov}\left(v_{i}, u_{i}\right)=0$.

The translog form of (1) is

$$
\begin{aligned}
\ln \left(y_{i}\right)= & \beta_{0}+\sum_{k} \beta_{k} \ln \left(x_{k i}\right) \\
& +0.5 \sum_{k} \sum_{p} \beta_{k p} \ln \left(x_{i k}\right) \ln \left(x_{i p}\right)+v_{i}-u_{i} .
\end{aligned}
$$

Under the following assumptions: (1) symmetry of $\beta_{k p}=\beta_{p k}$; (2) $v_{i}$ is a normal variable i.i.d, with constant variance $\sigma_{v}^{2}$; (3) any deviations from the frontier $u_{i}$ are assumed i.i.d and follow a normal distribution which is not correlated with $v_{i}$ $[19,20]$.
The variance of $u_{i}$ is

$$
\ln \left(\sigma_{u_{i}}^{2}\right)=\sigma_{0}+\sum_{j} \theta_{j} z_{j}+\varepsilon_{i},
$$

where $\theta_{j}$ are the estimators which capture the effect of the $z_{j}$ on the TE and $\varepsilon_{i}$ is the error term i.i.d, normal distributed.

5.1.1. Variables Specification. In (2), $y_{i}$ is the income of a farm $(i)$ in Fcfa. The inputs vector $x_{i}$ included four variables: acreage (in hectare), the quantity of labour (in man-day), the capital (in Fcfa), the intermediary inputs (in Fcfa), and others variables (see Table 1 ). The vector $z_{j}$ includes the amount of credit (in Fcfa), the credit square, and the interaction variables [14].

The elasticities of the inputs vector $x_{i}$ are expected to have a positive impact on the production level. Regarding the effects of the credit and the interaction variables on the TE, there is no assumption.

5.2. The Tobit Model. The human capital variables (age, gender, education level, etc.) are regressed on the TE scores to capture their marginal effects on the technical efficiency $[21,22]$. That is,

$$
Y_{i}^{*}=X_{i} \beta+\varepsilon_{i},
$$

where $Y_{i}$ is the dependent variable; $X_{i}$ are the independent variables vector to estimate; and $\varepsilon_{i}$ is the error term normally distributed, having a null mean and a constant variance $\sigma_{\varepsilon_{i}}$. Given that, for a farm $i$, the TE scores vary between 0 and 1 , it leads to

$$
\begin{gathered}
Y_{i}=Y^{*} \quad \text { if } 0<Y^{*}<1 ; \\
Y_{i}=0 \quad \text { if } Y^{*} \leq 0 .
\end{gathered}
$$

Therefore the empirical model is

$$
Y_{i}^{*}=\beta_{0}+\sum_{n=1}^{11} \beta_{n} X_{i}+\varepsilon_{i} .
$$

The Maximum likelihood model is used to avoid the errors noticed in the OLS model [23].

\section{Results and Discussion}

6.1. Descriptive Statistics. With an average of 44 years old, farmers interviewed are mostly men (90\%). The average household size is 10 members and the area under crops is 6.09 hectares on average. Most household heads are married (96.25\%); but less has been to formal school (46.47\%) and traditional school (33.03\%). All the respondents are in contact with extension services.

The variables in (2) were divided by their arithmetic means so that their estimates are their elasticities. The logarithm allows controlling the data variability showed by standard errors. Table 2 presents a descriptive statistics of the quantitative variables included in the stochastic frontier and Tobit models. 
TABLE 1: Variables introduced in the stochastic frontier model.

\begin{tabular}{|c|c|c|}
\hline Variables & Definitions & Units \\
\hline \multicolumn{3}{|l|}{ Dependent variable } \\
\hline$y_{i}$ & Farm income & Fcfa \\
\hline \multicolumn{3}{|l|}{ Vector $x_{i}$} \\
\hline Capital & Agricultural materials costs & Fcfa \\
\hline Acreage & Area under crops & Hectare \\
\hline Labour & Quantity of labour & Man-day \\
\hline Intermediary inputs & Costs of chemicals (pesticides, herbicides, and fertilizers) & Fcfa \\
\hline Capital $^{2}$ & Threshold of agricultural materials investment & - \\
\hline Acreage $^{2}$ & Threshold of area under crops & - \\
\hline Labour $^{2}$ & Threshold of labour used & - \\
\hline Intermediary inputs $^{2}$ & Threshold of chemicals used & - \\
\hline Capital $\times$ acreage & Interaction capital and acreage & - \\
\hline Capital $\times$ labour & Interaction capital and labour & - \\
\hline Capital $\times$ intermediary inputs & Interaction capital and intermediary inputs & - \\
\hline Acreage $\times$ intermediary inputs & Interaction acreage and intermediary inputs & - \\
\hline Acreage $\times$ labour & Interaction acreage and labour & - \\
\hline Labour $\times$ intermediary inputs & Interaction labour and intermediary inputs & - \\
\hline \multicolumn{3}{|l|}{ Vector $z_{j}$} \\
\hline Credit & Given amount & Fcfa \\
\hline Credit $^{2}$ & Threshold & - \\
\hline Credit $\times$ acreage & Interaction credit and acreage & - \\
\hline Credit $\times$ capital & Interaction credit and capital & - \\
\hline Credit $\times$ labour & Interaction credit and labour & - \\
\hline Credit $\times$ intermediary inputs & Interaction credit and intermediary inputs (pesticides, herbicides, etc.) & - \\
\hline
\end{tabular}

Source: authors' calculations.

TABLE 2: Descriptive statistics of the variables in the stochastic frontier and Tobit models.

\begin{tabular}{|c|c|c|c|c|c|}
\hline Variables & Units & Means & S.E & Minimum & Maximum \\
\hline Age & Years & 44.23418 & 11.22224 & 21 & 80 \\
\hline Farming experience & Years & 21.91983 & 11.07947 & 1 & 55 \\
\hline Household size & Number of people & 10.80842 & 6.604174 & 1 & 54 \\
\hline Revenue & Fcfa & 2262566 & 4016968 & 7500 & 34100000 \\
\hline Acreage & Hectare & 6.090127 & 8.310743 & 0.36 & 84 \\
\hline Intermediary inputs & Fcfa & 645453.1 & 1165424 & 15100 & 14100000 \\
\hline Labour & Man-day & 4.192144 & 3.126197 & 0 & 22.25 \\
\hline Capital & Fcfa & 712020.4 & 2670723 & 0 & 31100000 \\
\hline Credit & Fcfa & 35213.09 & 67563.82 & 0 & 761429 \\
\hline
\end{tabular}

Source: authors' calculations.

6.2. The Stochastic Frontier Model. The one-step stochastic frontier model applied relies on [16] application. The farming revenue 2,262,566 $( \pm 4016968)$ Fcfa is diversely affected by the production inputs. The model indicates that an increase of the acreage and the quantity of labour positively affects the revenue. In fact, an increase up to $1 \%$ of these inputs increases the farms output by $0.32 \%$ and $0.55 \%$, respectively. The same effect (positive) is noticed for an increase in the same range of the intermediary inputs expenses (pesticide, herbicides, fertilizers, etc.). A $1 \%$ increase in the expenses to purchase pesticides, herbicides, fertilizers, and so forth increases the output up to $0.86 \%$. Previous studies have reported that an increase in the use of pesticides, herbicides, fertilizers, acreage, and labour contributed to a higher yield [24]. Regardless of their positive elasticities, the use of these inputs needs to be regulated based on the values of their thresholds. Indeed, for the double of the average values of each input; only acreage ${ }^{2}$ increases the farms output up to $0.15 \%$ with a significance of $10 \%$. It is worth to note that, the positive effect of acreage ${ }^{2}$ is less important than the effect of acreage and is less significant also (see the Appendix). Doubling the quantities of labour, intermediary inputs (pesticides, herbicides, and fertilizers), and agricultural materials reduces the revenue by $-0.064 \%,-0.156 \%$, 


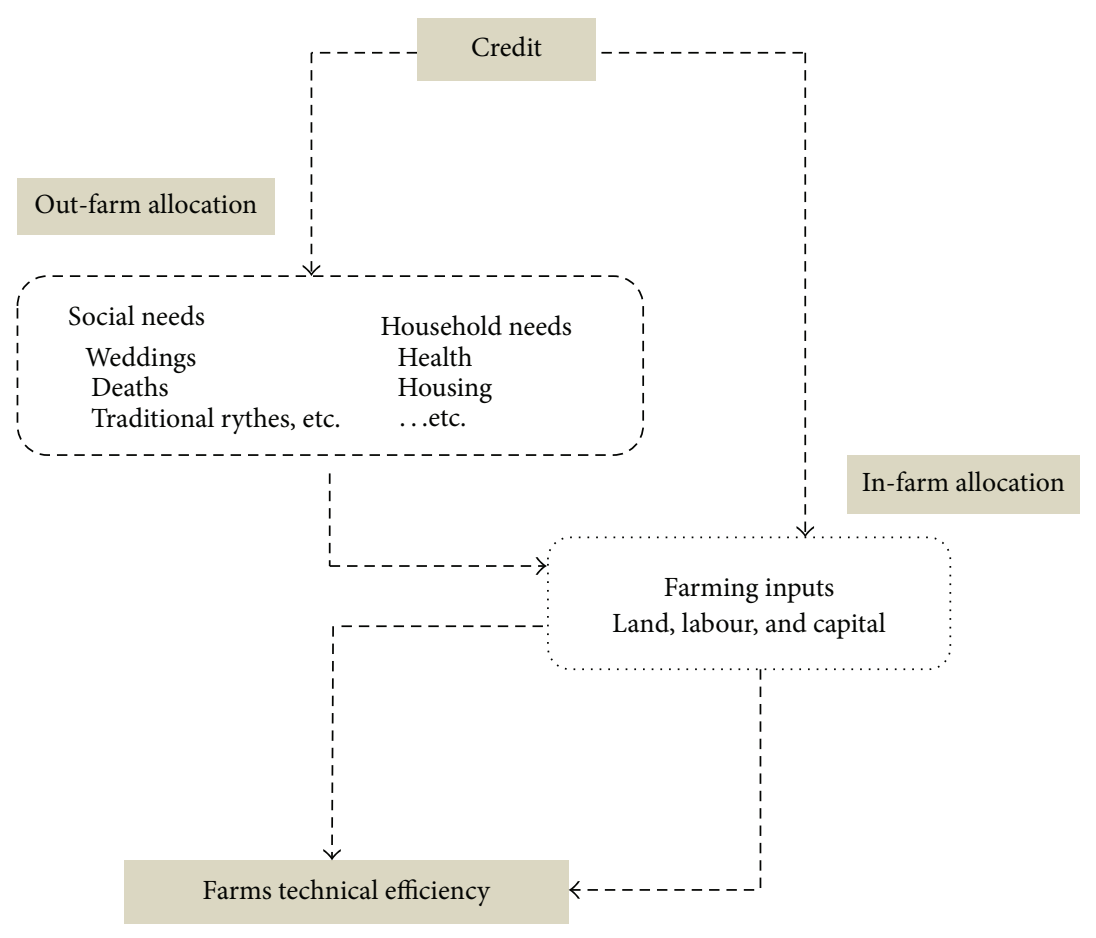

FIGURE 1: Farmers credit allocation schemes model. Source: authors' representation.

and $-0.025 \%$, respectively. On the side of the interactions between inputs, only capital $\times$ labour increases the revenue up to $0.04 \%$, meaning that a better combination of the labour to use the agricultural materials leads to higher income. A positive effect was expected from the interaction of labour $\times$ intermediary inputs on the revenue, but it is not the case. The reasons may be the overuse of pesticides and fertilizers and difficulties to master the agricultural process; which faces climate variability issues.

\subsubsection{Credit Allocation Schemes Effects on Farms Technical} Efficiency. The average technical efficiency score is 0.6752943 $( \pm 0.137443)$. The scores are diversely distributed across farms, with a median score that is equal to 0.7132979 . The difference between the mean and the median of the technical efficiency score is validated by the negative sign of the Skewness coefficient $(-0.7272118)$. Farmers credit allocation behaviours can be categorized in two allocations contexts: out-farm allocation and in-farm allocation (see Figure 1).

When farmers use the credit obtained to pay their debts, for weddings, death ceremonies, and others, the credit is invested towards out-farm purposes. The out-farm context includes the schemes (a) and (b). The scheme (b) identifies the credit threshold and the extent to which doubling the given amount of credit can positively impact farms technical efficiency. On the other hand, the in-farm context is when farmers invest the credit given towards farming purposes. This context includes the schemes (c), (d), (e), and (f), which identify farmers decision to invest to increase or improve their production inputs (see Table 3). To design farmers credit allocation model, we assume that each context (out-farm and in-farm) corresponds to more than $50 \%$ of the amount of credit invested for each purpose. The assumption is based on the notification that smallholder farmers do not invest all the credit towards a specific context, either out-farm or in-farm. That means that for in-farm purposes, a farmer may invest $70 \%$ of the given credit and the rest for out-farm goals. The opposite is observed for out-farm investments; $30 \%$ of the given credit is used for farming process.

The schemes (a) and (b) regard the context where farmers use the given credit for out-farm purposes (see Table 3). In the scheme (a), farms are less efficient for an increase of $1 \%$ of the credit amount given; this was expected due to the fact that more than $50 \%$ of the credit is not oriented into farming production. The scheme (b) concerns the same context and presents the level to which an increase of the credit amount given may positively affect farms TE. The model shows that doubling the average amount of credit given has no effect on the production system: no degree of significance and no error standard. And moreover the coefficient sign is negative. The credit amount should not exceed the threshold of credit ${ }^{2}$. Regarding the scheme (a) it should not reach the threshold because is it mostly used for out-farms purposes. The schemes (c), (d), (e), and (f) correspond to the credit used for farming purposes. In this context, the schemes (e) and (f) are significant but have opposite effects on the TE of the production system. The credit invested to purchase better quality of pesticides, herbicides, fertilizers, and so forth allows an improvement of the technical efficiency for an increase up to $1 \%$ of this investment (see Table 4 ), while an increase of the credit investment, in the same range, to have more workers distorts the farms efficiency by $-0.00000549 \%$. 
TABLE 3: Allocation schemes, contexts, and definitions.

\begin{tabular}{lcll}
\hline Inputs & Schemes & Contexts & Definitions \\
\hline Credit & (a) & Out-farm & Credit to debts refunding, weddings, deaths, housing, and so forth \\
Credit $^{2}$ & (b) & & Doubling the given amount (threshold) \\
\hline Credit $\times$ capital & (c) & & Credit to increase agricultural materials \\
Credit $\times$ acreage & (d) & In-farm & Credit to increase acreage \\
Credit $\times$ intermediary inputs & (e) & & Credit to increase pesticides, herbicides, and so forth \\
Credit $\times$ labour & (f) & & Credit to increase workers \\
\hline
\end{tabular}

Source: authors' calculations.

TABLE 4: Effects of credit allocation schemes on farms technical efficiency.

\begin{tabular}{|c|c|c|c|}
\hline $\mathrm{TE}$ & & $0.6752943( \pm 0.137443)$ & \\
\hline Inputs & Schemes & Elasticities & $P>|t|$ \\
\hline Credit & (a) & $-0.0000135(0.00000633)$ & $0.033^{* *}$ \\
\hline Credit $^{2}$ & (b) & $-0.00000000000364(-)$ & - \\
\hline Credit $\times$ capital & (c) & $0.000000488(0.00000166)$ & 0.769 \\
\hline Credit $\times$ acreage & (d) & $-0.00000428(0.0000052)$ & 0.410 \\
\hline Credit $\times$ intermediary inputs & (e) & $0.00000873(0.00000522)$ & $0.094^{*}$ \\
\hline Credit $\times$ labour & (f) & $-0.00000549(0.00000287)$ & $0.055^{*}$ \\
\hline
\end{tabular}

Note: ${ }^{* * *, * * *}$ significant at $10 \%, 5 \%$, and $1 \%$, respectively.

Source: authors' calculations.

This result suggests that a better use of the labour may be reached through the use of family labour, allowing reducing production costs related to workers payments.

The schemes (c) and (d) are expected to be significant and both positive, but these schemes are not significant. The allocation of the credit to increase the acreage increases farms inefficiency by $-0.00000428 \%$, meaning that a wider farm lead to greater related inputs costs and to more difficulties to master the agricultural process. Therefore, the scheme (d) does not allow improving technical efficiency. This result is supported by the effects of acreage ${ }^{2}$ and acreage on the revenue, which were positive but less increasing for an increase of the area under crops from acreage to acreage ${ }^{2}$. Then investment in land is not advisable to farmers.

The scheme (c), even though positive, is not significant, meaning that few farmers are involved in this scheme. Actually, smallholder farmers do not to improve the quality of the agricultural materials and the fewer that are so doing, are the ones with a higher level of education.

6.3. The Tobit Model. Gender and household size significantly reduces farms technical efficiency (Table 5). A shift of the household head gender from man to woman status diminished farms efficiency by $0.0656572 \%$. This result reveals women's limited access to production inputs: land, capital, and credit. In fact in rural area the assets are owned by the husband and he gives a part of these assets to his wife/wives. In this resources allocation scheme, women have to work with the husband before working on their own field. Then, with less time allocation to their own production it is technically difficult to them to be efficient. On the side of access to credit, women were left behind for having no assets; they face collateral issues to get credit. An increase of $1 \%$ of the household size reduces farms technical efficiency by $0.0034473 \%$. This unexpected result is supported by the sign of the variable labour ${ }^{2}$ in (2), meaning that there is a threshold that farmers must not exceed. This threshold may equal the quantity of labour obtained from an average household size of $10.80842( \pm 6.604174)$ persons. According to the literature variables such as household head age, education level, and farming experience, access to extension services may significantly influence farms technical efficiency but they do not.

This fact may be explained as follows: most farmers are young, $44.23418( \pm 11.22224)$ years in average. And this fact does not facilitate credit access due to collateral issues, which are often required in kind (land or houses). In rural area and for farmers, these assets can be valued as collateral after several years of savings then cannot be owned by young farmers. Moreover, with an average $21.91983( \pm 11.07947)$ years in farming and $53.52 \%$ with no access to formal education, it is difficult for farmers to adapt to environmental variations and master new agricultural technologies.

\section{Conclusion}

Using the one step stochastic frontier model the study captures credit allocation schemes and identifies the ones that improve farms technical efficiency. Estimations reveal that out of six only three schemes have significant effect on technical efficiency and from these three just one scheme has positive effect on the technical efficiency: scheme (e). Therefore, farmers that use the given credit to purchase better quality of fertilizers, pesticides, and herbicides are likely to improve their farms efficiency. This efficiency can also be 
TABLE 5: Tobit model results.

\begin{tabular}{lccc}
\hline Variables & Coefficients & $P>|t|$ & Expected signs \\
\hline Age & $-0.0002498(0.0009398)$ & 0.790 & + \\
Gender & $-0.0656572(0.0238994)$ & $0.006^{* *}$ & Men $+/$ women - \\
Education & $-0.003613(0.0145079)$ & 0.803 & + \\
Extension service & $0.0105402(0.0241567)$ & 0.663 & + \\
Household size & $-0.0034473(0.0010865)$ & $0.002^{* *}$ & + \\
Farming experience & $0.0013197(0.0009311)$ & 0.157 & + \\
Constant & $0.7451122(0.0432094)$ & $0.000^{*}$ & - \\
\hline
\end{tabular}

Note: ${ }^{* * *, * * *}$ significant at $10 \%, 5 \%$, and $1 \%$, respectively.

Source: authors' calculations.

TABLE 6: Results of stochastic frontier with conditional mean model.

\begin{tabular}{|c|c|c|c|}
\hline Variables & Coefficients & Standards errors & $P>|t|$ \\
\hline \multicolumn{4}{|c|}{ Lrevenu } \\
\hline cons & 0.5639018 & 0.0789205 & $0.000^{* * *}$ \\
\hline lcapital & 0.0258756 & 0.0193221 & 0.181 \\
\hline lacreage & 0.3210206 & 0.0588239 & $0.000^{* * *}$ \\
\hline llabour & 0.5577022 & 0.0300458 & $0.000^{* * *}$ \\
\hline linterm_input & 0.0867108 & 0.049874 & $0.082^{*}$ \\
\hline $0,5 *$ lcapital $^{2}$ & -0.0252712 & 0.0144483 & $0.080^{*}$ \\
\hline $0,5 *$ lacreage $^{2}$ & 0.1591446 & 0.0946285 & $0.093^{*}$ \\
\hline $0,5 *$ llabour $^{2}$ & -0.0645713 & 0.0262547 & 0.014 \\
\hline $0,5 *$ linterm_input ${ }^{2}$ & -0.1568689 & 0.0810997 & $0.053^{*}$ \\
\hline Lcapital × lacreage & -0.0481295 & 0.0354144 & 0.174 \\
\hline Lcapital × llabour & 0.0495199 & 0.0160244 & $0.002^{* *}$ \\
\hline Lcapital $\times$ linterm_input & -0.0241044 & 0.0265636 & 0.364 \\
\hline Lacreage $\times$ linterm_input & 0.0604558 & 0.080368 & 0.452 \\
\hline Lacreage $\times$ llabour & 0 & (omitted) & \\
\hline linterm_input $\times$ llabour & 0.035108 & 0.0333955 & 0.293 \\
\hline \multicolumn{4}{|c|}{$\mathrm{Mu}$} \\
\hline Credit & -0.0000135 & $6.33 e-06$ & $0.033^{* *}$ \\
\hline Credit $^{2}$ & $-3.64 e-12$ & . & . \\
\hline Credit $*$ lcapital & $4.88 e-07$ & $1.66 e-06$ & 0.769 \\
\hline Credit $*$ lacreage & $-4.28 e-06$ & $5.20 e-06$ & 0.410 \\
\hline Credit $*$ linterm_input & $8.73 e-06$ & $5.22 e-06$ & $0.094^{*}$ \\
\hline Credit $*$ llabour & $-5.49 e-06$ & $2.87 e-06$ & $0.055^{*}$ \\
\hline Sigma_v2 & 0.1377795 & 0.0323337 & - \\
\hline Sigma_u2 & 0.5679396 & 0.1314753 & - \\
\hline Sigma2 & 0.7057191 & 0.1101696 & - \\
\hline Gamma & 0.8047672 & 0.0680913 & - \\
\hline
\end{tabular}

Note: ${ }^{*, * *, * * *}$ significant at $10 \%, 5 \%$, and $1 \%$, respectively

Source: authors' calculations.

technically improved by the scheme (c), with a prerequisite which is farmers' better access to education. This condition will make them willing to accept change for improvements of their agricultural materials.

\section{Conflict of Interests}

The authors declare that there is no conflict of interests regarding the publication of this paper.

\section{References}

\section{Appendix}

See Table 6.
[1] DPP/MAE, Rapport de performance secteur agricole, Direction de la Programmation et de la Prospective, Ministère de l'Agriculture, de l'Elevage et de la Pêche, Cotonou, Bénin, 2010. 
[2] K. Z. M. Kodjo, E. H. Abiassi, and M. C. Allagbé, Le financement de l'agriculture béninoise dans un contexte de libéralisation: contribution de la microfinance, FSA, Université d'Abomey-Calavi, Cotonou, Bénin, 2003.

[3] A. Singbo, Analyzing efficiency of vegetable production in Benin [Ph.D. thesis], Wageningen University, 2012.

[4] D. Lesaffre, "Quels financements pour l'Agriculture des Pays en Développement?" Revue Grain de Sel, no. 16, 2000.

[5] T. Sossa, "Microfinance et inclusion financière au Bénin," in La Microfinance au Bénin, The Graduate Institute Publications, Geneva, Switzerland, 2011.

[6] R. Saldias and S. von Cramon-Taubadel, Access to Credit and the Determinants of Technical Inefficiency among Specialized Small Farmers in Chile, Department für Agrarøkonomie und Rurale Entwicklung, Universität Gøttingen, 2012.

[7] H. H. Komicha and B. Öhlmer, "Influence of credit constraint on technical efficiency of farm household in Southeastern Ethiopia," in Proceedings of the International Conference on African Development Archives, Paper 125, 2007.

[8] S. Ayaz and Z. Hussain, "Impact of institutional credit on production efficiency of farming sector: a case study of District Faisalabad," Pakistan Economic and Social Review, vol. 49, no. 2, pp. 149-162, 2011.

[9] K. K. Bolarinwa and E. O. Fakoya, "Impact of farm credit on farmers socio-economic status in Ogun State, Nigeria," Journal of Social Science, vol. 49, no. 1, pp. 67-71, 2011.

[10] T. S. Hyuha, B. Bashaasha, E. Nkonya, and D. Kraybill, "Analysis of profit inefficiency in rice production in Eastern and Northern Uganda," African Crop Science Journal, vol. 15, no. 4, pp. 243253, 2007.

[11] S. C. Kumbhakar and C. A. K. Lovell, Stochastic Frontier Analysis, Cambridge University Press, Cambridge, UK, 2000.

[12] S. Kumbhakar, S. Ghosh, and J. T. McGuckin, "A generalized production frontier approach for estimating determinants of inefficiency in U.S. dairy farms," Journal of Business \& Economic Statistics, vol. 9, no. 3, pp. 279-286, 1991.

[13] D. Reifschneider and R. Stevenson, "Systematic departure from the frontier: a framework for the analysis of firm inefficiency," International Economic Review, vol. 32, pp. 715-723, 1991.

[14] A. Dinar, G. Karagiannis, and V. Tzouvelekas, "Evaluating the impact of agricultural extension on farms' performance in Crete: a nonneutral stochastic frontier approach," Agricultural Economics, vol. 36, no. 2, pp. 135-146, 2007.

[15] C. J. Huang and J. Liu, "Estimation of a non-neutral stochastic frontier production function," The Journal of Productivity Analysis, vol. 5, no. 2, pp. 171-180, 1994.

[16] G. E. Battese and T. J. Coelli, "Frontier production functions, technical efficiency and panel data: with application to paddy farmers in India," Journal of Productivity Analysis, vol. 3, no. 1-2, pp. 153-169, 1992.

[17] Z. Griliches, "Estimation of the aggregate production functions from cross sectional data," Journal of Farm Economics, vol. 45, pp. 419-428, 1963.

[18] A. Zellner, J. Kmenta, and J. Dreze, "Specification and estimation of Cobb-Douglas production function models," Econometrica, vol. 34, pp. 784-795, 1966.

[19] S. B. Caudill, J. M. Ford, and D. M. Gropper, "Frontier estimation and firm-specific inefficieny measures in the presence of heteroskedasticity," Journal of Business and Economic Statistics, vol. 13, no. 1, pp. 105-111, 1995.
[20] B. Brümmer and J. Loy, "The technical efficiency impact of farm credit programmes: a case study of Northern Germany," Journal of Agricultural Economics, vol. 51, no. 3, pp. 405-418, 2000.

[21] D. O. Nyagaka, G. A. Obare, and W. Nguyo, "Economic efficiency of smallholder rish potato producers in Kenya: A case of Nyandarua North District," in Proceedings of the International Association of Agricultural Economists' Conference, Beijing, China, August 2009.

[22] G. A. Obare, D. O. Nyagaka, W. Nguyo, and S. M. Mwakubo, "Are Kenyan smallholders allocatively efficient? Evidence from Irish potato producers in Nyandarua North district," Journal of Development and Agricultural Economics, vol. 2, no. 3, pp. 7885, 2010.

[23] D. N. Gujarati, Basic Econometrics, McGraw-Hill, New Delhi, India, 4th edition, 2004.

[24] K. Bakhsh, L. Hassan, and A. Maqbool, "Factors affecting cotton yield: case study of Sargodha (Pakistan)," Journal of Agriculture \& Social Sciences, vol. 1, no. 4, pp. 332-334, 2005. 

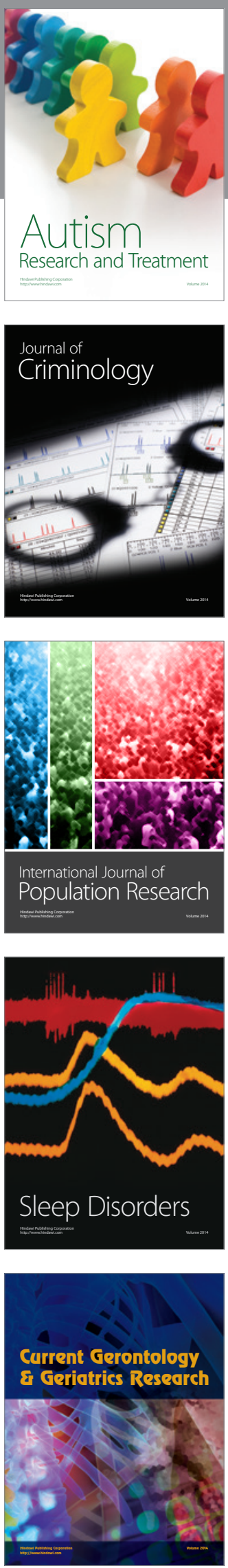
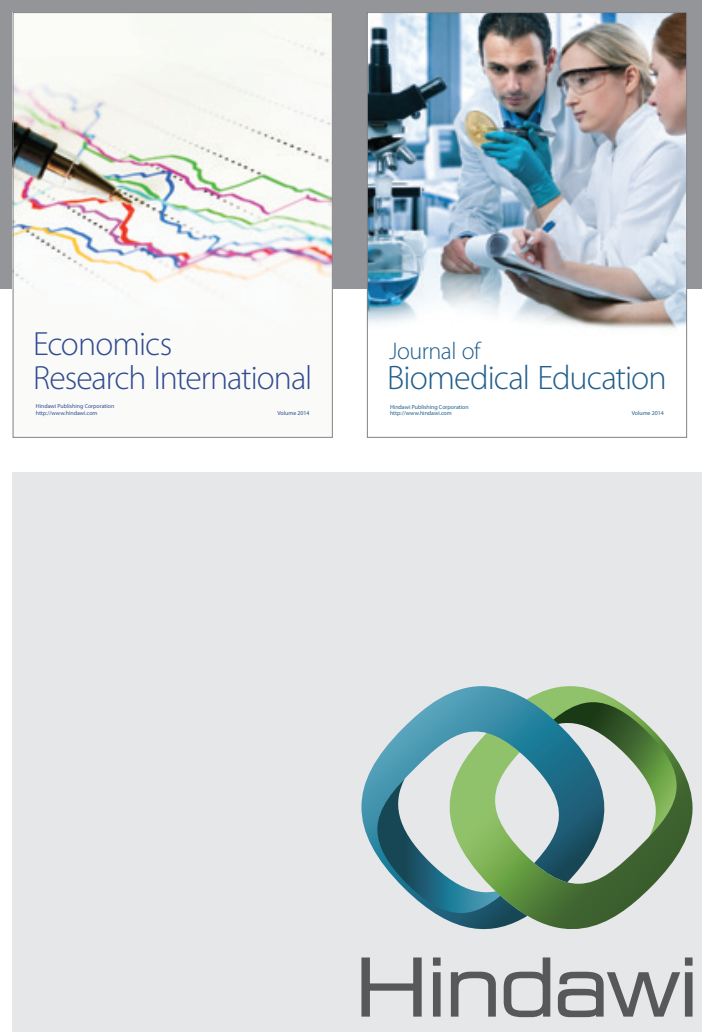

Submit your manuscripts at

http://www.hindawi.com
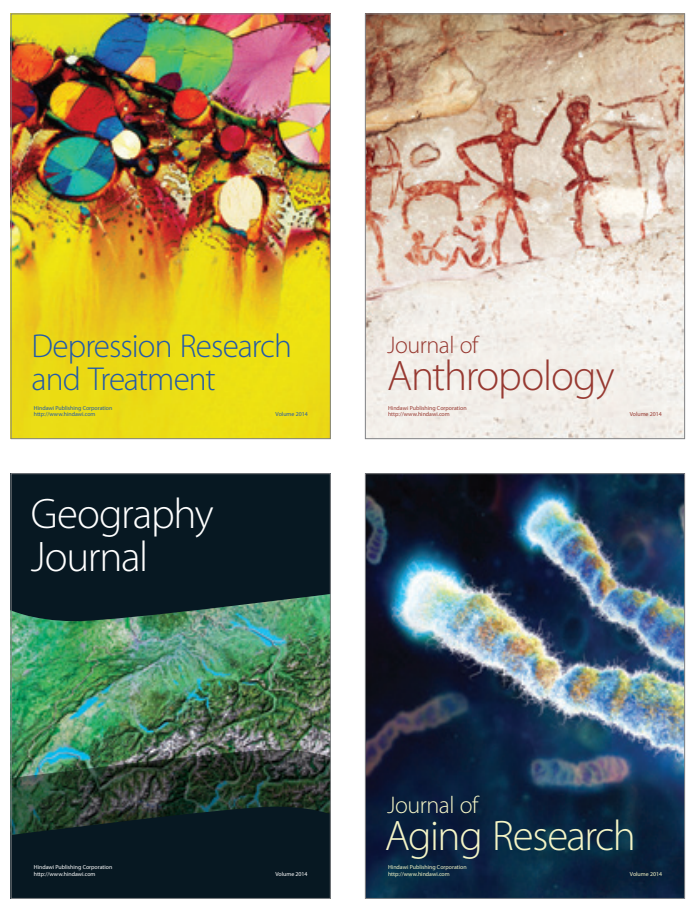
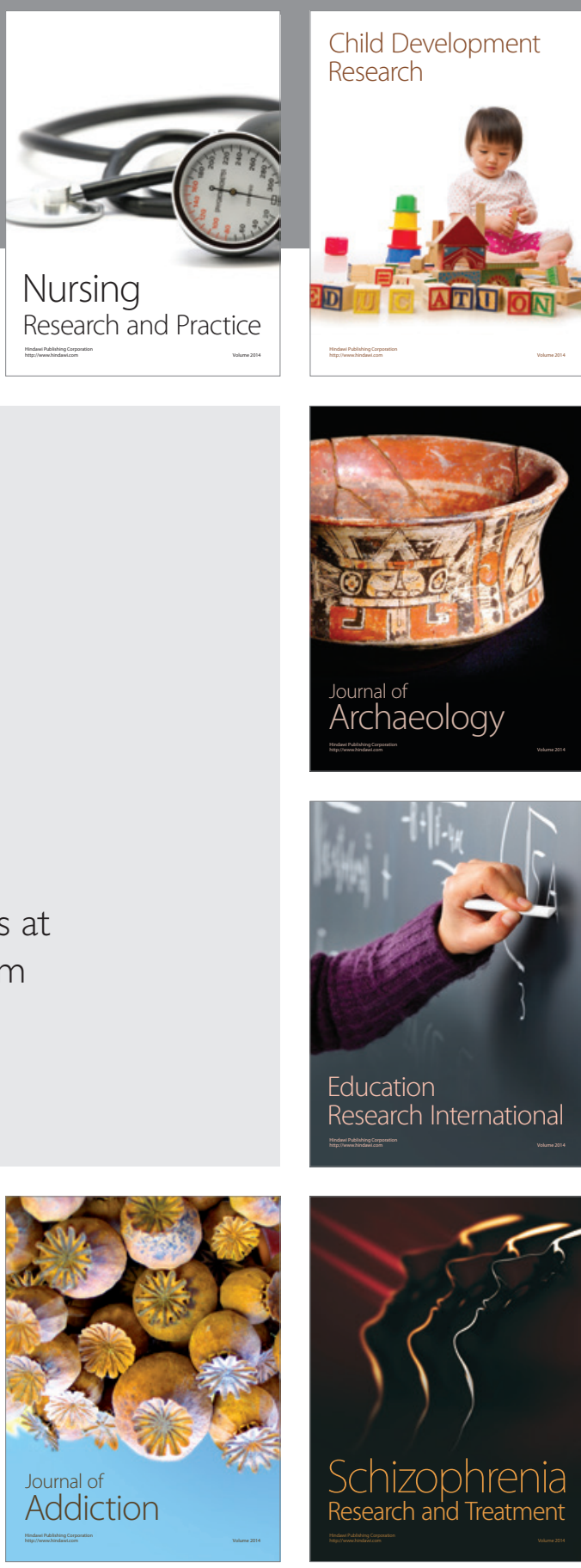

(D)
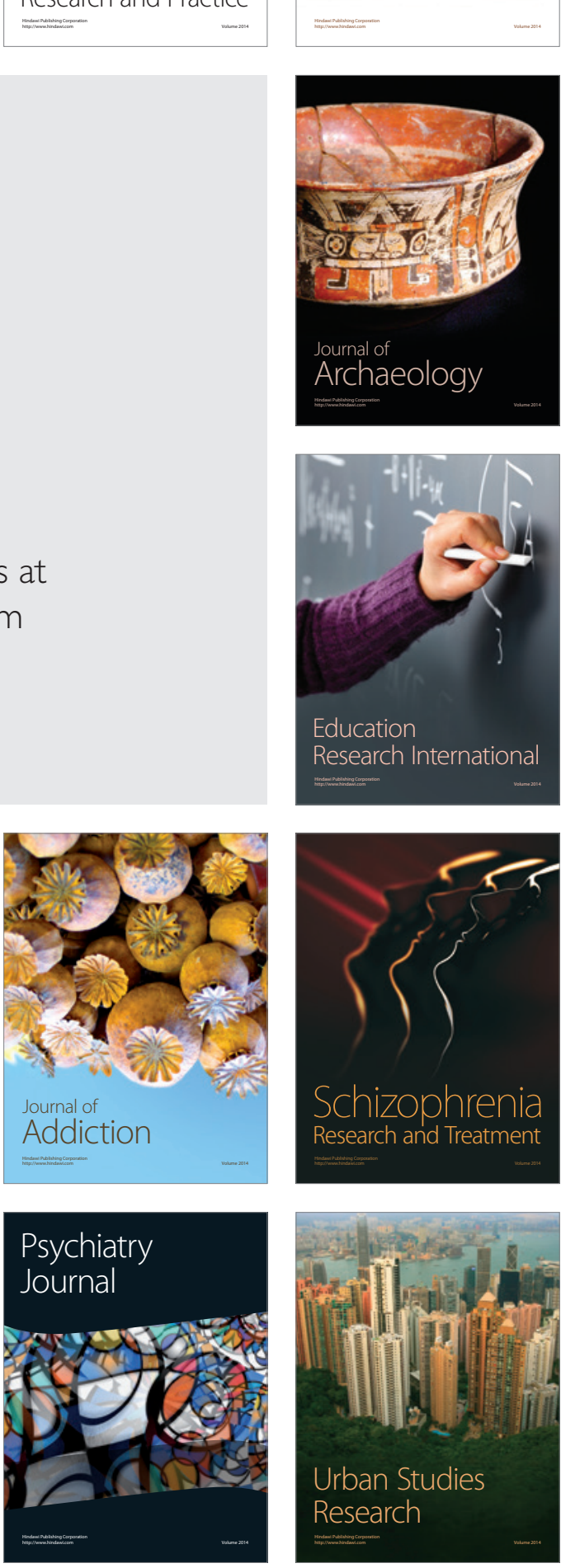